\title{
Functional Risk Management Model to Evaluate the Strategic Sustainability of Road Freight Transport Enterprises
}

\author{
Ekaterina A. llyina* \\ Chuvash State Pedagogical University named after IY Yakovlev, Russian Federation \\ *Corresponding Email: kaviyana@mail.ru \\ Svetlana V. Grigoreva \\ Russian state social University, Russian Federation \\ Tatiana V. Dmitrieva \\ Russian State Social University, Russian Federation
}

Doi:10.5901/mjss.2015.v6n6s7p110

\begin{abstract}
The article is devoted to the actual problem of regional development - the development of a functional model of risk management in assessing the strategic sustainability of freight transport companies in the region. The article discusses the concept of 'strategic stability of freight transport companies'. Application of the process approach reasoned in this study. To model the business process of risk management in assessing the strategic sustainability of freight transport companies, the authors propose a IDEF methodology. Based on this methodology is proposed functional model of risk management in assessing the strategic sustainability of freight transport companies, including context diagram, context diagram of decomposition diagrams. The basic operation of risk management in assessing the strategic sustainability of freight transport companies: risk classification, risk management planning, risk identification, risk analysis, risk assessment, risk treatment, monitoring and control risks. Methodical bases of allocation of risks temporal and spatial stability study management issues of strategic stability of freight transport companies. In order to identify risks provided a method of scoring. Risk assessment of the strategic sustainability of freight transport companies carried out using the theory of fuzzy sets. Based on fuzzy logic ranked risks temporal and spatial stability in the development of freight transport companies. The authors propose a method to minimize the risks of strategic stability of freight transport companies based on strategic outsourcing. Substantiated transfer into a strategic outsourcing of functions related to the analysis of long-term factors and trends of the company and the region, the development of predictive estimates to achieve the strategic objectives of the freight transport companies. Testing of a functional model of risk management in assessing the strategic sustainability of freight transport companies carried out by the example of the Chuvash Republic.
\end{abstract}

Keywords: process approach, methodology IDEF, risk management, strategic sustainability, strategic outsourcing

\section{Introduction}

Risk management is a subject of many scientific papers (Aven \& Renn, 2010; Crouhy et al., 2005; Pozdeyev, 2013), normative documents, including ISO standards (The IDEF0 methodology, 1993), determining the quality management systems of the enterprise. Standards should serve an integral part of quality management and decision-making in all areas of management. This also applies to economic and social, and environmental performance that meets the requirements of the sustainable development of the enterprise. In order to maintain an effective risk management system, it is important to create the company's corporate culture, vision, mission and goals of all members of the workforce. One can express the way that risk management is everyone's business, as workers in their places had better understanding of the causes, consequences and the likelihood of risk.

Risk management requires an integrated approach. This is because the enterprise in modern conditions are faced with a number of different risks (e.g. political, economic, technological, social, environmental), which do not confront any individual risk without attention to the others. Thus, the concept of "'esidual risk' arises, which may contain unidentified risk. Thus, risk management should be comprehensive, defined as a continuous process with a focus on the prospect of achieving the strategic goals. Only such approach will help achieve the strategic objectives, keeping the strategic stability 
of the enterprise.

The strategic stability of the cargo motor transportation enterprise (CMTE) means the preservation of long-term upward trend of development, expressed complex targets determined by economic, social and environmental characteristics of the company, taking into account achievable transport development of the territory. Strategic management of CMTE based on temporal expression (i.e. characterized by the upward trend of development) and spatial (i.e. transport is characterized by development of the territory to ensure access of economic entities to natural and human resources) stability.

An integrated approach to risk management requires constant evaluation of the potential risks of activities, summarizing the results of the choice of priorities for management decisions. This approach should be integrated in the development strategy of the company as an integral element of the overall strategic management system. An integrated approach aimed not only at minimizing or at reducing risks; it will also contribute to the support of activities related to innovation and technology upgrading. This will ensure the optimum balance between tactical and strategic decisions on the development of the enterprise.

There are many different risk management tools, one of which is the process approach. In the 80 years, it complicates the process of production, exacerbated competition and increases the growth of corporations. All this has led to is the emergence in the west of the concept of the process approach to management. Process approach consisted of interacting business processes, each of which is in the form of graphical design. All business processes consist of a sequence of operations with the chain-adjusted responsibility and have the final value for the consumer in the form of creating a product or service. To further optimize or restructure used a detailed analysis of the control system by constructing a simplified model of the company.

\section{Modeling of Business Risk Management Process when Evaluating of Strategic Sustainable Development of Enterprises}

In this paper, we consider the process approach to risk management when evaluating of strategic sustainability of the CMTE. For the modeling of business risk, management process when evaluating of strategic sustainability of CMTE, the IDEF (i.e. Integration DEFinition) methodology is applied. IDEF methodology views any of the studied system as a set of interacting and interconnected blocks, reflecting the processes, operations, actions that occur in the system under study.

The objectives of the modeling business process of risk management when evaluating of strategic of sustainable development of CMTE are: Indication of the main risk management processes; Identifying links between processes; Formation mechanisms in the process of risk management; Disclosing resources required to manage the risks.

Model of risk management when evaluating the sustainable development strategy of CMTE reach the goal if:

1) The classification of risks,

2) The risks identified when evaluating strategic of sustainable development of CMTE,

3) Risks are analyzing,

4) The risks are assessing,

5) Develop and implement methods of risk treatment, risk reduction activities,

6) The risks are controlling and monitoring.

Process model 'Risk Management when evaluating strategic of sustainable development of CMTE' includes: context diagram, containing the inputs, outputs, resources and mechanisms of the model and the decomposition diagram of context diagram that shows the relationships between the elements of the model.

Figure 1 shows a context diagram of risk management models when evaluating sustainable development strategy of CMTE, built using IDEF0 methodology in software product AllFusionProcessModeler 7 (BPwin), components of which are: Information on the retrospective assessment of CMTE, information about the market situation, the management plan for the strategic development of resistance CMTE (input); A report on the assessment of the effectiveness of risk management measures (output); Documents regulating the activities CMTE, regulations on risk management, risk management tools (tools and methods); A group of experts, the deputy director for strategic development, risk managers, specialists in control, logistical, financial and informational resources (resources).

Decomposition of context diagram represents the basic operations that must be performed in the modeling business risk management process when evaluating of strategic of sustainable development of CMTE: risk classification, risk management planning, risk identification, risk analysis, risk assessment, risk treatment, monitoring and control risks. 


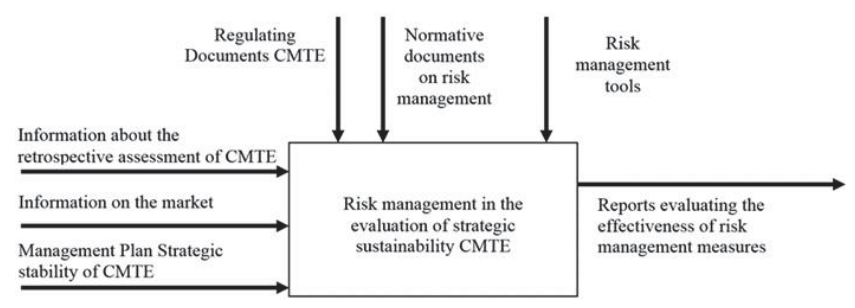

Figure 1. The context diagram A-O 'Risk Management when evaluating strategic of sustainable development of CMTE'

\section{Basic Operations in the Modeling Business Risk Management Process when Evaluating of Strategic Sustainable Development of Enterprises}

\subsection{Risks classification}

Before assessing the market situation and understanding the possible causes of risk, it is necessary to classify the risks that could significantly affect the state of strategic stability in the long-term development of the enterprise. Strategic management of CMTE based on the temporal and spatial expression of stability, respectively, classify the risks of strategic stability must be based on these concepts, etc., highlight the risks of temporal and spatial stability (Grigoreva, 2014). Risks of temporal stability divided by short-term (mid-term) and long-term risks. The first risk may occur in 3 years, the second - in the period from 3 to 10 years.

Short-term (mid-term) risks associated with the risk of incorrect assessment of the short-term (mid-term) factors in the development of the enterprise, the downside risks to the economic potential and the risk of loss of liquidity and solvency of the company. The long-term risks associated with long-acting factors, which include tactical, technological, social, legal and environmental factors. These factors determine the development trends of the economy and the region, and the associated risks at the enterprise level. These include the risk of incorrect assessment of trends in the development of the enterprise, the forecast risk and the risk of failure to reach the strategic goals of the enterprise.

All identified risks have a direct impact on strategic sustainability of CMTE. Defining development trends helps answer the question of how well the company manages the financial and non-financial assets during the analyzed period, how to effectively use their own capital. Positive trends in the development of enterprises will testify about it, and negative - will characterize the gaps in enterprise management.

Risks of spatial stability are dividing into two groups: business risks and regional risks. The first group of risks related to the scope of activity of business partners, which include banks and investment funds, as well as suppliers and customers of freight motor transport enterprise. As part of this investment can be identified (credit) risk, the risk of loss of competitiveness of services, reputation risk, and, finally, the risk of losing customers. These risks in the event of their manifestation certainly complicate the implementation of the strategy of the enterprise. The second group consists of regional (country) risks associated with political and economic situation in the country. These include the risk of changes in economic conditions, technological, legal, demographic and environmental risks. These risks may adversely affect the ability to attract investments (loans), financial results, liquidity, and the implementation of environmental activities eventually, the strategic stability CMTE.

\subsection{Risk Management Planning}

The inputs of the planning process of risk management are information about the retrospective assessment of CMTE, information about the market situation, the management plan for the strategic development of resistance CMTE. It is also necessary to consider the factors that affect the formation of the level of demand for freight transportation (llyina, 2013).

The operation of risk management planning should form a risk management plan, which describes the general approach to risk management in the project, their classification, methods for identifying and responding. At the heart of the risk management plan are documents regulating the activities CMTE, regulations on risk management, specific methods to reduce the negative impact of adverse events on the management of strategic stability of CMTE. The risk management plan of the project includes a description of the risk factors; description of the risk profile; required resources; management measures for each risk; measures to inform people about the status of project risks; the critical routes of the plan. 


\subsection{Identification of risks}

This operation involves the precise definition of tendencies of development CMTE, which in turn depend on retrospective assessment of the correct development of the enterprise. Risk Identification is the process of identifying the risks that may affect the control system of strategic stability CMTE, and a description of their characteristics.

To identify risks of temporal and spatial stability CMTE, a method of scoring is proposed, taking into account the opportunities the SWOT-analysis and PEST-analysis to determine the potential risk coverage of the company's strengths and market opportunities (Grigoreva, 2014). The level of coverage of short-term risks of CMTE is higher than the longterm, which requires special training to identify trends in the development of both the company and trends at the regional level. Noteworthy is that the risks are covered by more than the strengths of the company, rather than the market opportunities. Therefore, the company needs more thoroughly explore the opportunities provided by the market environment, the banking sector, infrastructure, businesses and other market elements. Finally, we can draw attention to the risks of low scores coating that will adjust enterprise development program towards achieving the strategic goals of the enterprise.

The result of the process of risk identification is the risk map, comprising: to thwart the identified risks; list of response measures; the prerequisites for a risk, clarification of risk.

By identifying risks, we can get the new group, which will lead to a more expanded structure of the risks described in the risk management plan. Example of a risk map is shown in Table 1.

Table 1. Model form of risk maps

Risk identification

Period of risk validity Risk type Risk categorization Background of risk occurrence Implications Responsive events

\subsection{Risk analysis}

This operation includes selection of categories of resources; definition of requirements (regulatory, contractual, technical) resources; identify relevant threats and vulnerabilities for selected categories of resources; calculation of the probability of threats and vulnerabilities.

\subsection{Risk assessment}

Based on the developed structure of risks, reports on the identification and analysis of risks, taking into account the risk assessment techniques, Ryhtikova (2007) takes calculated risks and a comparison of the risks to a predetermined scale of the risk. The study of Grigoreva (2013) demonstrates the advantage of fuzzy logic approach to traditional approaches for risk assessment of strategic stability CMTE. Fuzzy logic, proposed in 1965 by the American mathematician L. Zadeh (1976), is the first point of view, which operates with inaccurate or even not quite clear concepts.

Risk assessment of the strategic sustainability CMTE using the theory of fuzzy sets is doing in several stages. We introduce the basic concepts of the theory of fuzzy sets.

1. Introduce the so-called 'linguistic variables' that are set on a quantitative scale, and take values in the form of combinations of words. One of the linguistic variables is 'strategic risk' that has five values (i.e. fuzzy subset of states): 'the ultimate strategic risk', 'high strategic risk', 'medium strategic risk', 'low risk strategy', and 'little strategic risk'.

2. Settle hazards of temporal and spatial stability, which are subject to a comprehensive assessment.

3. Introduce a system of five membership functions corresponding keystone species for a given linguistic variable.

4. Form a group of experts.

5. Estimate and rank the current level of risk types.

6. Calculate the importance of each indicator for the risk of strategic stability of the motor transportation enterprise by rule Fishburne (1978).

7. Classify the current value of the degree of risk as a criterion for partitioning venture set into subsets.

8. Draw conclusions about the risk of temporal and spatial stability of the motor transport enterprise (linguistic recognition).

After the procedure of recognition of linguistic risk of strategic sustainable development of CMTE Chuvash 
Republic JSC 'Akkond-trans' using the method of fuzzy sets was complete, the following results were obtained: the risk of temporal stability of the enterprise can be estimated $30 \%$ as the lowest and $70 \%$ as a minor; the risk of spatial stability of the enterprise can be estimated $40 \%$ as the lowest and $60 \%$ as insignificant.

\subsection{Processing risk}

The goal of treatment is to change the identified risks in order to achieve the development goals of the enterprise. The process of risk treatment is continuous and involves the study of options for handling each risk to an acceptable level of residual risk. It also includes selecting and implementing a method for processing the risk. Among the treatment options available to visit are risk avoidance methods, adoption, change, risk sharing. Methods such as avoidance, acceptance and change risk are static in nature and can be using to handle the risks of the current period. To minimize the risks of strategic stability of freight transport companies propose a method based on the use of strategic outsourcing.

Outsourcing is a versatile management tool, because its essence lies in the possibility of transferring some of the external executor functions of the organization as a whole or in part, as long life, and for a short period (see Augus et al., 2002; Baden-Fuller et al., 2000; Olson \& Wu, 2008; Sanders et al., 2007; Quinn \& Hilmer, 1994). Strategic outsourcing based on the changes and continuous adaptation of the company to changing market conditions. Its main distinguishing feature is a long-term relationship in which the two sides focused on the implementation of the strategic objectives of the enterprise. As the relationship develops, in this case for a long time, this leads to a strengthening of the partnership the enterprise-customer and the outsourcer, and to increase the skills and knowledge of employees.

Conceptually, strategic outsourcing has the following positions: choice of outsourcer; outsourcing contract; risks associated with outsourcing. For effective outsourcing the relations between the parties should be developed in the context of the strategic development of the company, which is the central element in the choice of outsourcer. Selecting an outsourcer requires an entity to analyze its features and function definitions for the transmission 'aside'. An important condition for this must be specialty enterprise in the field of economic analysis and forecasting by using advanced technology in this direction. The transfer of the functions of the outsourcer will enable the company to simplify the work of the development and implementation of company strategy, and, consequently, to minimize the risks of strategic stability. In this respect, one can divide the factors that are associated with the risks of strategic stability and distribute their analysis between the enterprise-customer and the outsourcer as follows (Figure 2).

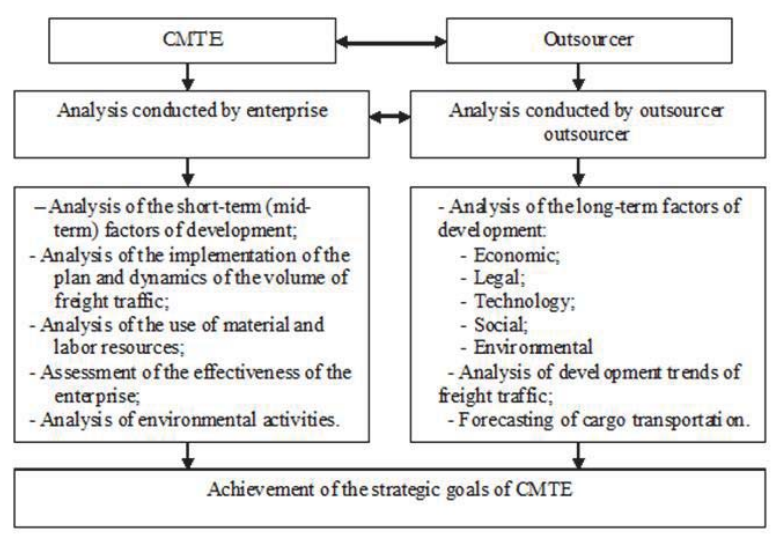

Figure 2. Distribution of analytical procedures between the freight transportation company and the outsourcer

A strategic outsource company can significantly reduce operational risks. At the same time, the implementation of strategic outsourcing contract may entail risks associated with the performance of the contract. The reasons for this may be different, in particular: The goals are not clearly defined on implementing the functions transferred to outsourcer; employees of the outsourcer did not have sufficient experience of the work on economic analysis and forecasting trends in the development of political, economic, technological and other factors; erroneous economic assessment of the current situation to meet the challenges of outsourcing; insufficient consideration of social and environmental factors in justifying the sustainable development of the enterprise; insufficiently developed feedback mechanism in the relations between the 
outsourcer and the client; insufficient protection of information; the presence of unidentified risks in conducting analytical procedures on risk assessment.

Strategic outsourcing is quite a powerful tool for ensuring strategic stability of CMTE. However, to ensure the efficiency of its use is necessary to conduct in-depth analytical and organizational work objectively evaluate not only the expected current results, but also long-term effects of the individual functions by external organizations - outsourcers.

\subsection{Monitoring and controlling risks}

Risk Monitoring and Control is the process of responding to the risks, tracking identified risks, monitoring residual risks, identifying new risks and assessing the effectiveness of risk management measures. The monitoring and risk management decisions on changing the risk management plan, risk maps, methods of minimizing risks and compiled a report on the evaluation of the effectiveness of risk management measures.

\section{Conclusion}

Risk management with business processes enables to respond more quickly to changes in the management of strategic stability and development of CMTE control. Classic risk management methods are time-tested and effective, but the use of modern tools, will help strengthen the 'weak points' in the management of strategic stability of CMTE and make the strategic goals more stable and confident.

\section{References}

August, B.G., \& Hao, Y., \&Weigand, M. (2002). The Other Side of Outsourcing. The McKinsey Quarterly, 1, 53-54.

Aven, T., \& Renn, O. (2010). Risk Management and Risk Governance. Berlin, Springer-Verlag, 290.

Baden-Fuller,C., \& Targett, D., \& Hunt, B. (2000). Outsourcing to outmanoeuvre: outsourcing re-defines competitive strategy and structure. European Management Journal, 18 (3), 285 -295.

Crouhy, M., \& Galai, D., \& Mark, R.M. (2005). The Essentials of Risk Management. New York, NY: McGraw-Hill, 432.

Fishburn, P. (1978). Utility theory for decision making. Moscow, M.: Nauka, 352.

Grigoreva, S. V. (2013). Assessment of strategic risks to the sustainability of the enterprise with the use of fuzzy set theory. Innovative development of economy, 4-5(16), 117-122.

Grigoreva, S. V. (2014). Factors and methods of risk analysis strategic stability of the enterprise. Transport Russia, 1 (110), 123-126.

Ilyina, E. A. (2013). Evaluation of the influence of transport network for economic development of the region. Ars Administrandi, 2, 91-97. Olson, D.L., \& Wu, D. (Eds.). (2008). New Frontiers in Enterprise Risk Management. Berlin, Springer-Verlag, 229.

Pozdeyev, V. L. (2013). Standardization management analytical risk management: a conceptual approach. Issues of Economics and law, 3, 153-158.

Quinn, J. B., \& Hilmer, F. G. (1994). Strategic outsourcing. Sloan management review, 35 (4), 43-55.

Ryhtikova, N.A. (2007). Analysis and risk management: a Training manual. Moscow, M: FORUM: INFRA-M, 240.

Sanders, N.R., \& Locke, A., \& Moore, C.B., \& Autry, C.W. (2007). A multidimensional framework for understanding outsourcing arrangements. Journal of Supply Chain Management: A Global Review of Purchasing and Supply, 43(4), 3-15.

The IDEFO methodology. Standard. The Russian version. (1993) Moscow, M: Metatechnology, 107.

Zadeh, L. (1976). The concept of a linguistic variable and its application to approximate reasoning. Moscow, M: Mir, 167. 